\title{
Analysis of the Quality Levels of Sports Organizations in Instanbul and Kocaeli as Percieved by those Living in those Provinces
}

\author{
ERDAL BAL ${ }^{1}$, NEDIM MALKOÇ ${ }^{2}$ \\ Department of Exercise and Sport Sciences, University of Health Science, Turkey, \\ Correspondence to Dr Erdal BAL, Email. erdal.bal@sbu.edu.tr,
}

\begin{abstract}
Background: Sports organizations are important for their promotion on the physical, economic, and socio-cultural changes and transformations in space and urban fabric.

Aim: The aim of this study is to analyze the quality levels of sports activities in Istanbul and Kocaeli as perceived by people living in these two provinces.

Methods: 519 people, 289 residing in Istanbul and 230 residing in Kocaeli, were included in the study. $53.2 \%$ of these are female and $46.8 \%$ are male. The questionnaire consists of two parts. First section consists of a 10 -item questionnaire for demographic information of individuals created by the researcher, while the second part includes 25-question, four-dimensional scale named Inventory of Perceived Quality and Image at Sport Organization Scale (IPQISO).

Results: Results show that the male participants had higher scores than female participants $(p=0,002)$, participants with good economic status had higher scores than others, and the scores of athletes participating in sports activities were higher than others' $(p<0,001)$.

Conclusion: Consequently, participants living in Istanbul province had higher scores in quality perception than those living in Kocaeli and the difference was statistically significant $(p<0,011)$.

Keywords: Global phenomenon, International conflicts, New world order, Professional sports activities, Urban landscape
\end{abstract}

\section{INTRODUCTION}

Today, sports activities are important for economic development especially in cities with industrial problems, as they ensure regional and local development of countries through prestige, advertisement, promotion, sports success, branding, marketing, and investment funds. Sports activities, which generally take place in cities, provide an enlightenment of the scope and an increase in the level of realization of the rapid urban development and transformation desired by central and local governments by focusing on the effects that they create. Sports organizations are important for their promotion on the physical, economic, and socio-cultural changes and transformations in space and urban fabric.

Although sociology has taken sport to the field of study as a social phenomenon in the last 60 years, archaeological finds and written documents show that sport has been an important activity since the first societies ${ }^{1}$. It is seen as a social participation, a business or entertainment ${ }^{2}$. According to Atasoy and Kuter, as a global phenomenon, sports became widespread depending on the socioeconomic conditions of societies ${ }^{3}$. Sports are also included in the phenomenon of consumption, which has accelerated the spread of globalization. In recent years, many types of sports have been formed and the number of audiences or participants is increasing rapidly. While it is expected that sports will help countries to develop and be balanced and sustainable in nature, today discussions abound of how sports have been helpful in shaping the world and what they try to express with their usefulness ${ }^{4}$. Over time, the process of professionalization has removed sporting activities from being a game and turned it into an economically functioning area ${ }^{5}$.

The phenomenon that shows the effect of each formation, project, organization, or structure primarily in humans is quality. What makes valuable for everything people consume is an affordable price and quality level. The same thoughts prevail in the sports organizations.

Since the quality sporting activities organized by sports organizations have an impact on the audience, then they are expected to consume quality time and money. The phenomenon of quality is represented by different expressions according to the place of use. The reason for this is the multi-dimensional evaluation of quality ${ }^{6}$, which may be due to the emphasis on consumer (customer) or manufacturing processes in different definitions ${ }^{7}$. The counterpart of faith, trust and satisfaction of the product in the market by consumers, or the status of ensuring the satisfaction of the service or product were received by consumers $^{8}$.

Therefore, the meaning of quality to humans includes;

- Meeting expectations and needs

- Satisfaction with the product or service in the market

- The absence of any deficiencies and defects of the product or service offered

- The positive trend of expectations is an important axis in clarifying the perception of quality that may occur in minds ${ }^{9}$.

New world order forces institutions and organizations to develop global strategies that are flexible, based on information, quality, multicultural and simplified as much as possible against competitors in the global market. The achievement of this can be seen in all institutions, big or small, which seems to depend primarily on success in the management process ${ }^{10}$. Sporting activities, especially in the 20th century, stand in a very different place in terms of the organization, massification, differentiation, globalization, diversification, politicization, secularization, professionalization, industrialization, commercialization, scientificization, gender neutralization, aesthetics and 
eroticization from a sociological perspective and continue to exist in a unique way that is full of innovations ${ }^{11}$ Accordingly, events and activities with a "culture" theme play an important role in the restructuring of the city economy in sports activities that develop in parallel with economic and technological conditions ${ }^{12,13,14}$.

Therefore, it has become imperative to provide stronger specialization, division of labor and coordination. Sports activities can cause bloody conflicts from time to time. While the apparent reasons for these conflicts could be due to a goal, a form of cheering, and an end of match tension, issues like religion, sectarian differences, and local problems can also lie behind international conflicts. Although not based on violence, tribune collapse and some panic accidents may cause deaths from time to time, and sometimes heart attacks and suicides come to the fore due to the outcome of some matches ${ }^{15}$.

Each sport activity has different features, even if there are repetitive activities in some sports. Since time, facilities, responsible persons and competitors, weather conditions will be different each time, more efforts should be placed and more expertise should be utilized at the planning stage than routine work, because detailed planning is required for such organizations.

Organizations have a common purpose, which is to provide jobs and benefits to specific positions and to run the organization in a healthy way ${ }^{16}$. The ability to detect, effect and correct all changes that occur to the original plan is the basis of the monitoring process. While the conditions considered in the planning of sports activities are regulated for implementation, they should be planned and evaluated according to the conditions that may develop apart from the current situation. All sports institutions and organizations should be equipped for adverse problems that may develop ${ }^{17}$.

A sport organization is an entity that is managed as a social personality or organization in the sports industry, which has a specific purpose, relatively clear boundaries, and a rational structure and functioning system. It has a planned and scheduled work pattern designed to carry out or organize and manage all kinds of sports activities and events that will take place within this framework ${ }^{18}$. It is also accepted as the referral and management of the tasks undertaken to plan and coordinate activities such as courses, meetings, panels, camps and so on ${ }^{19}$.

The sport organization takes into cognizance things that should be done in various stages of all the activities organized in relation to sporting events, what kind of deficiencies can be encountered and what should be done to eliminate these problems. This is because issues will be easily resolved when these phases are taken into account and there will not be problems ${ }^{20}$.

The most important feature of sporting activities is the need for timely, planned, and controlled works within a determined budget between dates that have been confirmed previously. At the same time, the success of an organization is associated with the completion of the organization within the time, cost, and performance constraints $^{21}$.

When we look at the possibilities that may lead to the emergence of risks during an activity, we encounter factors such as change of internal / external conditions, ignorance, uncertainty, uncontrolledness, planlessness and no program, distancing from the facts, time shortage, limited resources, unlimited demands, complex activities, stress, high working tempo 22 .

Cultural and social infrastructures must be constructed in a sustainable manner in line with certain plans and programs in order to integrate sports activities in cities with urban life and to contribute to social life in such cities.

The contributions of such large events on a local and national scale can be listed in general and specifically as follows:

General purposes.

- To contribute to raising a healthy society as a public service within the framework of social purpose

- To provide equal opportunity to all citizens through sports

- To promote sports branches throughout the country and to spread sports branches

- To train successful athletes and sportsmen

- To help improve the nature of urban landscape

- To ensure the development of sports culture in the cities

- To strengthen sports infrastructure in cities $23,24,25$.

- $\quad$ Specific purposes.

- To provide financial gain

- To encourage political superiority

- To facilitate advertising and marketing ${ }^{26,27}$.

\section{MATERIAL \& METHODS}

The universe of the research consists of individuals residing in the cities of Istanbul and Kocaeli. The sample of the study consists of 289 residents living in Istanbul and 230 individuals living in Kocaeli.

Frequency $(\mathrm{n})$ and percentage $(\%)$ values were made for categorical demographic variables and arithmetic mean, standard deviation, median, minimum and maximum values for non-categorical demographic variables was used. In comparison to demographic variables and scale scores; Independent sample $\mathrm{T}$ test was used to compare demographic variables with binary categories, and one-way analysis (ANOVA) was used in the analysis of more than two categories. Spearman correlation was used to compare quantitative variables and scale scores. In the study, the type I error rate was taken as 0.05 .

A questionnaire which consists of two parts was used in the research. The first section consists of a 10-item questionnaire for demographic information of individuals created by the researcher (age, gender, marital status, chronic diseases status, educational status, occupation, economic situation, participation in events, weekly sports duration, city of residence), and the second part includes 25-question, four dimensional scale named Inventory of Perceived Quality and Image at Sport Organization Scale (IPQISO) which was developed by Bayrakdaroğlu and Katkat ${ }^{28}$

\section{RESULTS}

While comparing the demographic information and scale scores of the participants, as shown in table 2, it was determined that the male participants had higher scores ( $p$ 
$<0.002)$ than their female counterparts. It was determined that there was no difference in marital status $(p=0,265)$, chronic illness conditions ( $p>0,269)$, educational status $(p=0,205)$ and occupational groups $(p=0,984)$ in terms of scale scores. It was determined that the participants, who stated their economic status as good, had higher scores than other participants $(p<0,001)$. It was determined that the participants who participated in sports events had higher scores $(p<0,001)$ than other participants. It was determined that the participants who performed sports more than 1 hour per week had higher scores $(p<0,001)$ than other participants. It was determined that the participants residing in Istanbul had higher scores $(p<0,011)$ than other participants. It was determined that there was no significant relationship between the participants' ages and scale scores ( $p>0,582)$.

Table 1: Demographic information of the participants

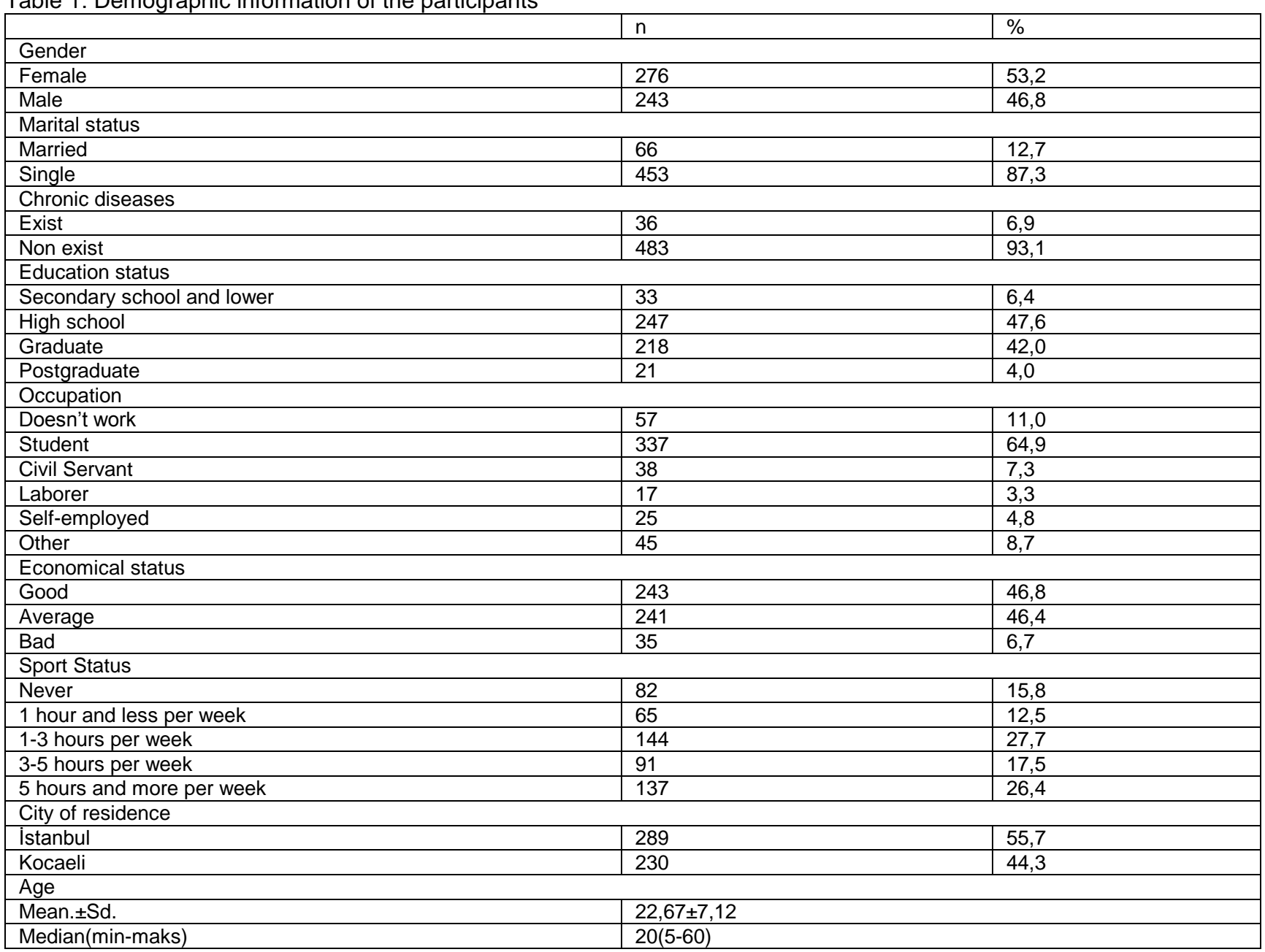

Table 2: Comparison of participants' demographic information and scale scores

\begin{tabular}{|c|c|c|c|c|c|}
\hline 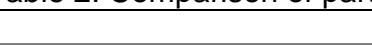 & Mean & Sd. & $\mathbf{T}$ & $p$ & Difference \\
\hline \multicolumn{6}{|l|}{ Gender } \\
\hline Female & 75,8696 & 30,89980 & \multirow[t]{2}{*}{$-3,142$} & \multirow[t]{2}{*}{$0,002^{*}$} & \\
\hline Male & 84,0700 & 28,53675 & & & \\
\hline \multicolumn{6}{|l|}{ Marital status } \\
\hline Married & 75,8485 & 27,46368 & \multirow[t]{2}{*}{$-1,117$} & \multirow[t]{2}{*}{0,265} & \\
\hline Single & 80,2715 & 30,41664 & & & \\
\hline \multicolumn{6}{|l|}{ Chronic diseases } \\
\hline Exist & 74,3611 & 31,09906 & \multirow[t]{2}{*}{$-1,106$} & \multirow[t]{2}{*}{0,269} & \\
\hline Non exist & 80,1077 & 29,98528 & & & \\
\hline \multicolumn{6}{|l|}{ Educational status } \\
\hline $\begin{array}{l}\text { Secondary school and } \\
\text { lower }\end{array}$ & 77,4242 & 32,46058 & \multirow[t]{2}{*}{1,534} & \multirow[t]{2}{*}{0,205} & \multirow[t]{2}{*}{-} \\
\hline High school & 82,6478 & 30,27236 & & & \\
\hline
\end{tabular}




\begin{tabular}{|c|c|c|c|c|c|}
\hline Graduate & 76,8165 & 29,83307 & & & \\
\hline Postgraduate & 78,7619 & 24,38628 & & & \\
\hline \multicolumn{6}{|l|}{ Occupation } \\
\hline Doesn't work & 77,2807 & 29,89610 & \multirow[t]{6}{*}{0,135} & \multirow[t]{6}{*}{0,984} & \\
\hline Student & 79,8576 & 31,11256 & & & \\
\hline Civil Servant & 81,5263 & 23,91396 & & & \\
\hline Laborer & 80,5882 & 31,12487 & & & \\
\hline Self-employed & 77,9200 & 24,93645 & & & \\
\hline Other & 80,8000 & 30,46429 & & & \\
\hline \multicolumn{6}{|c|}{ Economical Status } \\
\hline A & 84,7119 & 28,83380 & \multirow[t]{3}{*}{7,874} & \multirow[t]{3}{*}{$<0,001^{*}$} & \multirow[t]{3}{*}{$A>B, C$} \\
\hline B & 76,4357 & 30,64958 & & & \\
\hline C & 67,5143 & 28,60005 & & & \\
\hline \multicolumn{6}{|c|}{ A:Good B:Average C:Bad } \\
\hline \multicolumn{6}{|c|}{ Event participation status } \\
\hline Yes & 83,0993 & 28,67979 & \multirow[t]{2}{*}{5,215} & \multirow[t]{2}{*}{$<0,001^{*}$} & \\
\hline No & 64,7708 & 31,61262 & & & \\
\hline \multicolumn{6}{|c|}{ Weekly sports status } \\
\hline A & 62,2439 & 32,48155 & \multirow[t]{5}{*}{12,130} & \multirow[t]{5}{*}{$<0,001^{*}$} & \multirow[t]{5}{*}{$\mathrm{C}, \mathrm{D}, \mathrm{E}>\mathrm{A}, \mathrm{B}$} \\
\hline B & 71,8923 & 31,18149 & & & \\
\hline C & 82,9028 & 26,94058 & & & \\
\hline D & 87,6813 & 26,27584 & & & \\
\hline $\mathrm{E}$ & 85,2190 & 28,99333 & & & \\
\hline \multicolumn{6}{|c|}{ A: Never B: 1 hour and less per week C: 1-3 hours per week D: 3-5 hours per week E: 5 hours and more per week } \\
\hline \multicolumn{6}{|c|}{ City of residence } \\
\hline İstanbul & 82,7024 & 30,13894 & \multirow[t]{2}{*}{2,556} & \multirow[t]{2}{*}{$0,011^{*}$} & \\
\hline Kocaeli & 75,9478 & 29,61775 & & & \\
\hline \multicolumn{6}{|l|}{ Age } \\
\hline $\mathbf{R}$ & 0,024 & & & & \\
\hline $\mathbf{P}$ & 0,582 & & & & \\
\hline
\end{tabular}

\section{DISCUSSION}

The quality levels perceived by people residing in Istanbul and Kocaeli Metropolitan cities for sports activities were examined in this study. In the questionnaire consisting of 10 items regarding demographic information of individuals, results were obtained from age, gender, marital status, chronic diseases status, educational status, occupational status, economic status, participation in sports activities, weekly sports status, and city variables, and the differences in the level of quality perceived by individuals were evaluated.

A total of 311 subjects participated in the study of Okumuş and Duygun ${ }^{29}$, for the expected level of service and perceived quality in educational services. The age range of the subjects was 18-39. In the results of the study, there was no statistically significant relationship between the perceived quality level of the students' income and educational status. In our study, a similar result was obtained with the absence of a significant relationship in educational status. In the evaluation of income situations, results were obtained in the opposite direction of our study. In our study, it was concluded that the participants with high income had higher scores when compared to other participants. This situation is among the possible results considering the differences in the study, such as the sample group being different. The main reason why highincome participants have high scores in the quality they perceive is due to the fact that many organizations are followed in the city, the presence of important organizations and the separation of time and finance.

In the study carried out by Schijns et al. on the quality of sports services in clubs, it was observed that the companies within a quality service and organization have an impact on the satisfaction of their customers, and these situations also improved their sense of loyalty ${ }^{30}$. The concept of quality is a desired situation by individuals in the field of production and service. Meeting their expectations is considered as a possible result based on their loyalty and continuity to that brand, product, or organization.

Zeithaml et al. showed that when individuals are satisfied with the quality of the service they receive, there is an increased probability of positive behavior ${ }^{31}$. In the studies conducted, it was determined that when the degree of quality of the service provided increased, the level of participation in the organizations also increased ${ }^{32}, 33,34$. According to the study of Cronin et al., while examining the service industry, the audience expects quality from the sportsman it watches, the team it admires, the entertainment it wants, health, safety, social events, cafe, and eating places ${ }^{35}$. If these expectations are met, a certain level of satisfaction will be achieved in individuals. This satisfaction will influence many factors such as the behavior of the individuals, the city where it is located, the athletes there. In our study, men showed more satisfaction than women in sports organizations. Therefore, we conclude that men are able to encounter the organizational structure that they expect, while women encounter the organizational structure beyond their expectations, probably because they easily express their dissatisfaction with the deficiencies prevailing in qualities, activities and in the environment where they participate. Therefore, creating a more protective, entertaining, and comfortable environment for women in the specified cities and working towards meeting their expectations will enable a more effective organization to be formed.

2027 participants participated in the satisfaction and 
perceived quality study of Nuviala et al., to create prediction models on the customers of public and private professional sports services in Spain ${ }^{36}$. The study, which was attended by Spanish sports service users, consisted of $66.1 \%$ male and $33.9 \%$ female. The results obtained showed that the quality of the sports service received was good and high scores were obtained from technical factors and efficiency of staff. Quality expectation and interest showed variable rates according to different branches.

Rial et al. (2010) and Mañas et al. (2008) concluded that the human factor is a determining factor in the quality level in personnel and sports services in the same direction in the results of their studies 37,38 . From the results of our study, we concluded that men have higher perceived quality levels than women. At the same time, we observed that the income level, participation in sports activities, and the level of quality perceived by those who do sports more than an hour per week are higher than other participants. The fact that people with good income have the opportunities to go to national and international organizations is effective in creating such a result. People who do sports are more involved in sports, they follow and participate in the organization of sports in every aspect than other participants. Follow-up and participation will ensure that people are involved in many organizations. Especially if this situation has gained continuity, the person will show himself gradually in more professional organizations, and the quality of the organizations he visits will be at a high level accordingly. This is one of the expected results. The sports activities taking place in the province of Istanbul have higher level of quality than those in Kocaeli as seen from the results. This situation is also part of the expected results. The fact that İstanbul hosts more high-level sports activities than Kocaeli province, have more facilities, resources and opportunities, more investments in infrastructure, sports branches, have enabled such a result.

As it can be seen in the results of many studies, the factor that determines the quality level in sports organizations is the trained human factor, establishment, promotion, and marketing. It is likely that individuals working in sports services who do not have sufficient skills will experience some deficiencies and problems in the services that are provided within the organization. In this case, it may cause poor quality in terms of getting the services that people expect and want. The expectations of women should be

taken into consideration when sports events are to be held, and the establishment of a system that will allow for the participation of people with almost every income situation should be done. Differences between the provinces should be removed, and quality should be felt in the organization held in each region.

\section{CONCLUSION}

In the perceived quality level study of sports activities held in Istanbul and Kocaeli Metropolitan cities, a statistically significant relationship was found between men and women and it was found that men had higher scores than women $(p<0,002)$. There was no statistically significant difference between the marital status $(p>0,265)$, chronic illness $(p>0,269)$, educational status $(p>0,205)$, occupational groups ( $p>0,984)$ and age status $(p>0,582)$. It was observed that the participants with good economic status had the highest perception quality scores, and a significant difference was found between other participants $(p<0,001)$. It was also observed that the participants who are involved in sports activities had higher scores than those who are not $(p<0,001)$. The participants who do sports more than 1 hour per week, had higher scores in the quality level perceived from the organizations than those who never did or who only do 1 hour sports and the difference was statistically significant between them $(p<0,001)$. Therefore, we conclude that the quality level perceived by the sports organizations of the participants residing in Istanbul is higher than the participants residing in Kocaeli province $(p<0,011)$.

Increasing the participation of the sports organizations, advertising and promoting in a good way and the fact that the personnel involved in the organizations are related to the sports management and operation will increase the quality level. The perception formed in individuals is realized with the interest in the surrounding events. This means that all communication tools that may be of interest to people should be used in promotions and marketing. The use of individuals trained in sports management during sports organizations will be effective in building organizations with high quality. Emphasis should be placed on the field of management and organization, increasing the number of people trained in this field, and ensuring that they take part in more activities of the sports organizations.

\section{REFERENCES}

1. Bulgu N. Violence and Sub-Culture In Sport. Hacettepe J. of Sport Sciences. 2005; 16 (4): 229-250.

2. Basım N, Metin A. Sports Management. Ankara: Detay Publications; 2009

3. Atasoy B, Füsun ÖK. Globalization And Sports. Journal of Uludag University Faculty of Education 2005; XVIII (1): 1122.

4. Chappelet, JL. A Glocal Vision for Sport (and Sport Management), European Sport Management Quarterly, (Postface) 2009; 9(4): 483-485.

5. Talimciler A. Not Football but Business: Industrial football. Journal of Communication Theory and Research, Issue 26, Winter-Spring: 2008; 89-114.

6. Yatkin A. Total quality management, 3rd ed. Ankara: Nobel Academic Publishing; 2014.

7. Öztürk SA. Quality Dimensions and Increasing Quality in Service Industries. Journal of Verimlilik 1996; 2: 66-68.

8. Çelik A. Total Quality Management. 2nd ed. Ankara: Gazi Publications; 2010, 5-159.

9. Parlak S. Total Quality Management and Quality Management System Standards. Bursa Publication Distribution 2013, 5.

10. Düren Z. Management in the 2000s. Alfa Publishing and Distribution Co. Ltd. 2000.

11. İkizler HC. Social Sciences in Sports. Alfa Publishing and Distribution Co. Ltd. 2000; 109.

12. Zukin S. The Cultures of Cities, Black Well, Massachusetts; 2000.

13. Özdemir D. A Cultural Transformation Project in the City Center: Temple Bar,Dublin. Journal of Arredamento Architecture 2005; 03, 98-105.

14. Dündar GŞ. Cities in Pursuit of Title: An Overview of Mega Projects and Mega Events. Journal of Architecture 2010; 353: 53-58. 
15. Erkal, M.E., Güven, Ö., Ayhan, D. sports from a sociological point of view, Der Yayinlari, İstanbul: 1998;

16. Lehner E. Die Organisation als Männerbund. In Frauen und Männer in Organisationen und Leitungsfunktionen: Unbewusste Prozesse und die Dynamik von Macht und Gesellschaft, Edited by: Wolf, M. 2002;19-37. Frankfurt am Main: Brandes \& Apsel

17. Balcı V. Planning and Management of Sports Events. Ankara: Bagırğan Publications; 1999.

18. Slack T. Understanding Sport Organizations the Application of Organization Theory. Illinois: Human Kinetics Book; 1997.

19. Demirci N. Management-Organization and Organizations in Sports. Republic of Turkey Ministry of National Education, Youth and Sports General Directorate of Physical Training and Sport. Ankara : National Education Publications; 1986.

20. Inal AN. Introduction to Physical Education and Sports Science. Konya: Desen Offset Printing; 2000; 72-85

21. Gök Y, Balcı V. The Assessment of the Financial Dimension of the Sport Organizations in Terms of Risk Management. Ege Academic Review. 2012; 12: 61-69.

22. General Staff Land Forces Command. Risk Management Land Forces Publications Printed Documents Department 2009.

23. Roche M. Mega-Events and Modernity: Olympics and Expos in The Growth of Global Culture. London: Routledge; 2000.

24. Hughson J. Sport in the 'City of Culture' The Cultural Policy Connection' in International Journal of Cultural Policy, 2004 (10),3: 319-339.

25. Silk M, Amis J. Sport Tourism, Cityscapes and Cultural Politics, Sport in Society: Cultures, Commerce, Media, Politics 2005; 8:2, 280-301.

26. Karaca S. The Impact of Multi-Sport Events on the Cultural Developmental Dynamics of Cities: the Case of Erzurum and Trabzon in Turkey 2012; 4: 42-47.

27. Sunay, H. Organization in Sports. Ankara: Gazi Publications; 2010

28. Bayrakdaroglu,Y, Katkat D. A study on development of Perceived Quality-Image Scale in Sports Organizations. Journal of Human Sciences, 2018; 15(4): 2407-2416.

29. Okumuş A, Duygun A. Service Quality Measurement On
Education Services Marketing And Relationship Between Perceived Service Quality And Student Satisfaction Anadolu University Journal of Social Sciences, 2008; 8(2):17-38.

30. Schijns JMC, Caniels MCJ, Le Conte J. The Impact of Perceived Service Quality on Customer Loyalty in Sports Clubs. International journal of sport management recreation and tourism 2016; 24(C): 43-75.

31. Zeithaml VA, Berry LL, Parasuraman A. The behavioral consequencesof service quality. Journal of Marketing, 1996; 60(2): $31-46$

32. Kyle GT, Theodorakis ND, Karageorgiou A, Lafazani M. The effect of service quality on customer loyalty within the context of ski resorts. Journal of Park and Recreation Administration 2010; 28: 1-15.

33. Petrick JF, Backman SJ. An examination of the determinants of golf travelers' satisfaction. Journal of Travel Research, 2002; 40: 252-258.

34. Yuan J, Jang S. The effect of quality and satisfaction on awareness and behavioral intentions: Exploring the role of a wine festival. Journal of Travel Research, 2008; 46: 279-288.

35. Cronin JJ. Jr, Brady MK, Hult GTM. Assessing the effects of quality, value, and customer satisfaction on consumer behavioral intention in service environments. Journal of Retailing. 2000; 76(2), 193-218

36. Nuviala A, Grao-Cruces A, Pérez-Turpin, J A \& Nuviala R. Perceived service quality, perceived value and satisfaction in groups of users of sports organizations in Spain. Kinesiology, 2012; 44(1): 94-103.

37. Rial, J., Varela, J., Rial, A., \& Real, E. Modelización y medida de la calidad percibida en centros deportivos: La escala QSport-10. [Modelling and measuring perceived quality in sports centres: QSport-10 scale.]. RICYDE. Revista Internacional De Ciencias Del Deporte, 6(18), 2010; 57-73.

38. Mañas, M.A., Jiménez, G., Muyor, J.M., Martínez, V., \& Moliner, C.P. (2008). Tangibles as predictors of customer satisfaction in sports services. Psicothema, 20(2), 2008; 243-248. 